\title{
Proceedings of the ACM
} on Measurement and Analysis of Computing Systems 


\section{Proceedings of the ACM}

\section{on Measurement and Analysis of Computing Systems}

\section{ABOUT ACM}

ACM is the world's largest educational and scientific computing society, uniting educators, researchers and professionals to inspire dialogue, share resources and address the field's challenges. ACM strengthens the computing profession's collective voice through strong leadership, promotion of the highest standards, and recognition of technical excellence. ACM supports the professional growth of its members by providing opportunities for life-long learning, career development, and professional networking

Executive Director and CEO

Bobby Schnabe

Deputy Executive Director and COO Patricia Ryan

Director, Office of Information Systems Wayne Graves

Director, Office of Financial Services

Darren Ramdin

Director, Office of SIG Services

Donna Cappo

Director, Office of Publications

Scott E. Delman

ACM COUNCIL

President

Vicki L. Hanson

Vice-President

Cherri M. Pancake

Secretary/Treasurer

Elizabeth Churchill

Past President

Alexander L. Wolf

Chair, SGB Board

Jeanna Matthews

Co-Chairs, Publications Board

Jack Davidson and Joseph Konstan

Members-at-Large

Gabriele Anderst-Kotis; Susan Dumais; Elizabeth D. Mynatt: Pamela Samuelson; Eugene H. Spafford

SGB Council Representatives

Paul Beame; Jenna Neefe Matthews;

Barbara Boucher Owens

\section{REGIONAL COUNCIL CHAIRS}

ACM Europe Council

Dame Professor Wendy Hall

ACM India Council

Srinivas Padmanabhuni

ACM China Council

Jiaguang Sun

\section{BOARD CHAIRS}

Education Board

Mehran Sahami and Jane Chu Prey

Practitioners Board

Terry Coatta and Stephen Ibaraki
COMPUTER SCIENCE

TEACHERS ASSOCIATION

Mark R. Nelson, Executive Director

PUBLICATIONS BOARD

\section{Co-Chairs}

Jack Davidson; Joseph Konstan

\section{oard Members}

Ronald F. Boisvert; Karin K. Breitman; Terry J. Coatta; Anne Condon; Nikil Dutt; Roch Guerrin; Carol Hutchins:

Yannis loannidis; Catherine McGeoch;

M. Tamer Ozsu; Mary Lou Soffa;

Alex Wade; Keith Webste

\section{HEADQUARTERS JOURNALS STAFF}

Director of Publications

Scott Delman

Publications Operations Manager

Craig Rodkin

\section{Journals Manager}

Laura A. Lander

Assistant Editor

Stacey Schick

Bibliographic Processing Coordinator Anna Lacson

\section{Administrative Assistant}

Emily Eng

\section{EDITORIAL BOARD}

Editor-in-Chief

Augustin Chaintreau,

Columbia University

\section{Associate Editors}

Leana Golubchik,

University of Southern California

Zhi-Li Zhang,

University of Minnesota

\section{Advisory Board}

Leana Golubchik,

University of Southern California

Nidhi Hedge,

Bell Labs

Srinivasan Keshav,

University of Waterloo

Konstantina Papagiannaki,

Google

Mark S Squillante,

IBM Research

Adam Wierman

California Institute of Technology

Zhi-Li Zhang,

University of Minnesota
Editors

Murali Annavaram, University of Southern California Urtzi Ayesta, CNRS-LAAS \& Ikerbasque-UPV/EHU

Thomas Bonald, Telecom ParisTech

Sem Borst, Bell Labs, Eindhoven University of Technology

Niklas Carlsson, Linkoping University

Giuliano Casale, Imperial College London

Abishek Chandra, University of Minnesota

Cheng-Fu Chou, NTU

Florin Ciucu, Warwick University

Giulia Fanti, UIUC/CMU

Daniel Figueiredo, Federal University of Rio de Janeiro

Giuliana Franceschinis, Università, del Piemonte Orientale

"Amedeo Avogadro"

Lixin Gao, University of Massachusetts Amherst

Nicolas Gast, INRIA

Javad Ghaderi, Columbia University

Roch Guerin, University of Pennsylvania

Mor Harchol-Balter, CMU

Nidhi Hegde, Bell Labs

Longbo Huang, Tsinghua University

Sandip Kundu, University of Massachusetts Amherst

Marc Lelarge, INRIA,

Yanhua Li, WPI

Mingyan Liu, University of Michigan

Yi Lu, UIUC

John C.S. Lui, The Chinese University of Hong Kong

Laurent Massoulie, INRIA

Michela Meo, Polytechnic University of Turin

Vishal Misra, Columbia University

Eytan Modiano, MIT

Erich Nahum, IBM Research

Alexandre Proutiere, KTH

Konstantinos Psounis, University of Southern California

Dan Rubenstein, Columbia University

Stefan Schmidt, TU Berlin

Shubho Sen, AT\&T Research

Ramesh Sitaraman, University of Massachusetts Amhers

Mark Squillante, IBM Research

Peter Steenkiste, CMU

Sasha Stolyar, University of Illinois, Urbana-Champaign

Y.C. Tay, National University of Singapore

My Thai, University of Florida

Don Towsley, University of Massachusetts Amherst

Steve Uhlig, Queen Mary, University of London

Bhuvan Urgaonkar, Pennsylvania State University

Peter Van De Ven, CWI

Benny Van Houdt, University of Antwerp

Milan Vojnovic, Microsoft Research

Jia Wang, AT\&T Research

Adam Wierman, California Institute of Technology

Carey Williamson, University of Calgary

Cathy Xia, Ohio State University

Cheng-Zhong Xu, Chinese Academy of Science, Shenzhen

Advanced Institute of Technology/Wayne State

Li Zhang, IBM Research

Gil Zussman, Columbia University

\section{Information Director}

Giulia Fanti

UIUC/CMU 
ABOUT PROCEEDINGS OF THE ACM ON MEASUREMENT AND ANALYSIS OF COMPUTING SYSTEMS

PACM on Measurement and Analysis of

Computing Systems publishes original research of the highest quality dealing with performance of computing systems, broadly construed. We recognize that critical insights into key design trade-offs in computer or network systems have historically be obtained using a broad set of tools: benchmarking and experimental evaluation, mathematical modeling, algorithmic analysis, which often need to be combined creatively. This publication hence broadly welcomes works that further the state-of-the-art in determining or predicting the performance of computing systems and their applications. This includes efforts that creatively apply previously developed methods in systems, measurement and theory, and especially those combining results from multiple technical areas. Computing systems is broadly defined and includes in particular computer architecture, file and memory systems, database systems, computer networks, operating systems, distributed systems, web-based systems, data centers, cloud computing, large applications such as online social networks and wireless networks. Performance refers both to speed and the efficient use of various resources, including green computing for environmental sustainability.

Examples of performance evaluation methods include, among others, optimization, stochastic modeling and statistical analysis, instrumentation techniques and measurement design, workload characterization, formal methods for model verification, analysis of stochastic networks, and simulation.

\section{JOURNAL WEBSITE} http://pomacs.acm.org/

\section{SUBMISSIONS}

More details, including instructions for submitting to POMACS can be found at http:// pomacs.acm.org/

\section{SUBSCRIPTION, SINGLE COPY, AND} MEMBERSHIP INFORMATION

Subscription rates for POMACS are $\$ 150$ per year for ACM members, \$125 for students, and $\$ 425$ for nonmembers. Your subscription expiration date is coded in four digits at the top of your mailing label; the first two digits show the year, the last two show the month of expiration.

POMACS (ISSN: 2476-1249) is published in Spring and Fall by the Association for Computing Machinery (ACM), 2 Penn Plaza, Suite 701, New York, NY 10121-0701.

\section{Send orders to:}

ACM Member Services Dept.

General Post Office

PO Box 30777

New York, NY 10087-0777

For information, contact:

ACM Member Services Dept.

2 Penn Plaza, Suite 701

New York, NY 10121-0701

T: (212) 626-0500

$\mathrm{F:}$ (212) 944-1318

Email: acmhelp@acm.org

Order Online:

https://campus2.acm.org/public/qj/genpubqj/ publist/genpubqj_publist.cfm

\section{CHANGE OF ADDRESS NOTIFICATION.}

To notify ACM of a change of address, use the addresses above or send an email to: coa@acm.org.
Please allow 6-8 weeks for new membership or change of name and address to become effective. Send your old label with your new address notification. To avoid interruption of service, notify your local post office before change of residence. For a fee, the post office will forward 2 nd- and 3rd-class periodicals.

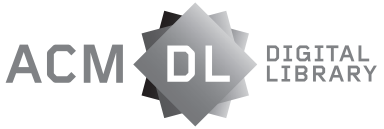

PACM is also available with a subscription to The ACM Digital Library (DL), the most comprehensive collection of full-text articles and bibliographic records in existence today covering the fields of computing and information technology. The full-text database includes the complete collection of ACM's publications, including journals, conference proceedings, magazines, newsletters, and multimedia titles.

dl.acm.org/POMACS

CONTACT POINTS

Copyright permission

permissions@hq.acm.org

Change of address

acmhelp@acm.org

PACM Subscriptions

https://campus2.acm.org/public/qj/genpubaj/ publist/genpubqj_publist.cfm

\section{ACM Code of Ethics}

http://www.acm.org/about-acm/ code-of-ethics

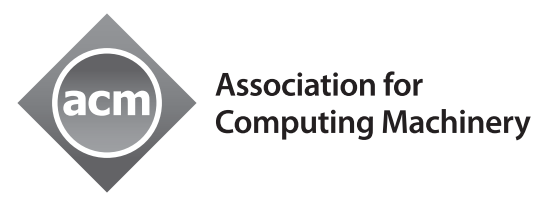

\section{ACM COPYRIGHT NOTICE}

Copyright $\odot 2017$ by the Association for Computing Machinery (ACM). Permission to make digital or hard copies of part or all of this work for personal or classroom use is granted without fee provided that copies are not made or distributed for profit or commercial advantage and that copies bear this notice and the full citation on the first page. Copyrights for components of this work owned by others than ACM must be honored. Abstracting with credit is permitted.

Authors refer to the retained rights section of ACM rights forms for exceptions around posting the accepted version. The full notice is available at www.acm.org/publications/policies/ copyright-policy\#permanent_rights. To copy or otherwise redistribute requires prior specific permission and/or a fee. Request permission to republish from: permissions@acm.org or fax Publications Department, ACM, Inc. Fax +1 212-869-0481. 